\title{
Evaluation of Antibacterial and Fluoride-releasing Adhesive System on Dentin - Microtensile Bond Strength and Acid-base Challenge
}

\author{
Mirela Sanae SHINOHARA ${ }^{1,2}$, Monica YAMAUTI ${ }^{3}$, Go INOUE ${ }^{3}$, Toru NIKAIDO ${ }^{3}$, Junji TAGAM ${ }^{3,4}$, \\ Marcelo GIANNINI ${ }^{1}$ and Mario Fernando DE GOES ${ }^{1}$ \\ ${ }^{1}$ Dental Materials Division, Department of Restorative Dentistry, Piracicaba School of Dentistry, State University of \\ Campinas, Piracicaba, SP, Brazil \\ ${ }^{2}$ Dental Materials Division, State University of Amazon, Manaus, AM, Brazil \\ ${ }^{3}$ Cariology and Operative Dentistry, Department of Restorative Sciences, Graduate School, Tokyo Medical and Dental Univer- \\ sity, Tokyo, Japan \\ ${ }^{4}$ Center of Excellence Program, FRMDRTB at Tokyo Medical and Dental University, Tokyo, Japan \\ Corresponding author, Toru Nikaido E-mail:nikaido.ope@tmd.ac.jp
}

Received April 14, 2006/Accepted June 23, 2006

\begin{abstract}
This study evaluated the influence of a fluoride-containing adhesive on microtensile bond strength ( $\mu$ TBS) to dentin, as well as analyzed the dentin-adhesive interface after acid-base challenge. Experimental groups were: G1 - Clearfil SE Bond control (SE); G2 - Clearfil Protect Bond control (PB); G3 - Primer[SE]/Adhesive[PB]; G4 - Primer[PB]/Adhesive[SE]. For $\mu$ TBS evaluation, dentin surfaces were ground, bonded, and composite resin crowns were built up to obtain beams to be tested. For interfacial analysis, adhesive system was applied on dentin surface and a low-viscosity resin was placed between two dentin disks. Then, the specimens were subjected to acid-base challenge, sectioned, and polished to be observed by SEM. $\mu$ TBS data showed no statistical differences among the groups (G1: 51.3, G2: 47.6, G3: 55.0, G4: 53.9; mean in MPa). Through SEM, it was observed that a thick acid-base resistant zone adjacent to the hybrid layer was created only when the fluoride-releasing adhesive was used. In conclusion, the presence of fluoride in an adhesive contributed significantly to preventing secondary caries, and did not interfere with dentin-adhesive bond strength.
\end{abstract}

Key words: Adhesive system, Dentin, Fluoride-releasing material

\section{INTRODUCTION}

The success of restorations hinges on the adhesion stability between composite resin and tooth structure. To maintain this adhesion stability, the presence of a hybrid layer is essential in that it forms a resistant structure against bacterial invasion. Currently, simplified systems such as self-etching primer/adhesive systems have demonstrated good clinical performance to dentin. This approach is less technique-sensitive and reduces the time required for the bonding procedure. Although advances in adhesive dentistry have brought about improvements in bonding systems and techniques, bond failures at the tooth-restoration interface remain a challenge in the dental field.

Microgaps between restorative materials and the cavity wall permit invasion of fluids and bacteria, leading to secondary caries. This occurs probably due to inadequate marginal adaptation of composite restorations ${ }^{1)}$. According to previous reports ${ }^{2,3)}$, secondary caries is the commonly cited reason for failure and replacement of restorations. Hence, antibacterial activity is considered to be an important beneficial property of dentin bonding systems for successful restorative treatments.

From this point of view, new versions of adhesive system containing fluoride in composition have been introduced in order to inhibit the action of secondary caries arising from enamel cracks or microleakage at the tooth-restoration interface. With regard to these fluoride-releasing restorative materials, some researchers have extensively demonstrated their significant cariostatic and antibacterial effects $^{4,5)}$.

An experimental two-step self-etching primer/adhesive system, ABF (former name of Clearfil Protect Bond) - composed of an antibacterial primer containing MDPB (12-methacryloyloxydodecylpyridinium bromide) and a fluoride-releasing adhesive - has shown the potential in artificial secondary caries inhibition around restorations ${ }^{6-8)}$. However, there is little information about the influence of antibacterial components on bonding strength. Likewise, information is scarce concerning antibacterial primer performance and fluoride-releasing adhesive effect against artificial caries challenge.

Tsuchiya et $a l .^{9)}$ described the formation of an acid-base resistant zone adjacent to the hybrid layer after acid-base challenge. Results of the study ${ }^{9)}$ clearly showed the influence of adhesive material composition in the formation of acid-base resistant zone. Although the characteristics of that resistant zone are still unclear, their results suggested the potential effect of self-etching primer adhesive systems in inhibiting secondary caries. 
Therefore, the purpose of the present study was to evaluate the influence of primer and bonding agent - by interchanging between a self-etching primer adhesive system with antibacterial properties (Clearfil Protect Bond) and a non-fluoride-containing self-etching primer adhesive system (Clearfil SE Bond) - on microtensile bond strength. In addition, in vitro inhibitory effect on artificial secondary caries around adhesive restorations was observed using a SEM.

\section{MATERIALS AND METHODS}

Table 1 lists the compositions, manufacturers, and batch numbers of the materials employed in this study.

Sixteen caries-free extracted human third molars were obtained under a protocol (\#023/2004) approved by the Ethical Committee at the Piracicaba School of Dentistry, State University of Campinas. Before use, the teeth were cleaned of debris and stored in physiological saline containing $0.1 \%$ thymol.

Experiment 1 - Microtensile bond test

1) Tooth specimen preparation

For each tooth, the coronal portion was removed to expose a flat, midcoronal dentin surface using a lowspeed diamond saw (Isomet 1000, Buehler Ltd., Lake Bluff, IL, USA) under water refrigeration (Fig. 1A). The exposed dentin surface was ground using 600grit silicon carbide abrasive paper under water stream for 60 seconds to produce a standardized smear layer (Fig. 1B).

2) Bonding and restorative procedures

Prior to adhesive application, the teeth were randomly assigned into four groups, according to the bonding procedures shown in Table 2. After applying the bonding resin, a composite resin, Clearfil AP -X, was built up using increments approximately 1 $\mathrm{mm}$ thick. Each increment was light-activated for 40 seconds (Optilux 500/Demetron-Kerr, Danbury, CT,

Table 1 Materials used in this study

\begin{tabular}{|c|c|c|c|}
\hline Material & Components & Batch Number & Manufacturer \\
\hline $\begin{array}{l}\text { Adhesive System } \\
\text { Clearfil SE Bond (SE) }\end{array}$ & $\begin{array}{l}\text { Primer: MDP, HEMA, water, PI, accelerators, } \\
\text { CA } \\
\text { Adhesive: MDP, HEMA, dimethacrylates, PI, } \\
\text { CA, microfiller }\end{array}$ & $\begin{array}{l}\text { Primer: 00507A } \\
\text { Adhesive: } 00712 \mathrm{~A}\end{array}$ & $\begin{array}{l}\text { Kuraray Medical } \\
\text { Inc., Tokyo, Japan }\end{array}$ \\
\hline Clearfil Protect Bond (PB) & $\begin{array}{l}\text { Primer: MDPB, MDP, HEMA, MFM, PI, } \\
\text { water } \\
\text { Adhesive: MDP, HEMA, MFM, PI, } \\
\text { microfiller, NaF }\end{array}$ & $\begin{array}{l}\text { Primer: } 000010 \\
\text { Adhesive: } 000017\end{array}$ & $\begin{array}{l}\text { Kuraray Medical } \\
\text { Inc., Tokyo, Japan }\end{array}$ \\
\hline $\begin{array}{l}\text { Restorative Material } \\
\text { Clearfil AP-X }\end{array}$ & $\begin{array}{l}\text { Bis-GMA, TEGDMA, barium glass filler } \\
(85 \mathrm{wt} \%), \mathrm{PI} \text {, accelerators }\end{array}$ & 01063A & $\begin{array}{l}\text { Kuraray Medical } \\
\text { Inc., Tokyo, Japan }\end{array}$ \\
\hline Metafil flo & $\begin{array}{l}\text { 2,2-Bis }[4 \text {-(methacryloxy- } \\
\text { polyethoxy) phenyl }] \text { propane, bifunctional } \\
\text { methacrylate monomers, silica, } \\
\text { 3-(trimethoxysilyl) propyl methacrylate }\end{array}$ & GS1 & $\begin{array}{c}\text { Sun Medical, } \\
\text { Moriyama, Japan }\end{array}$ \\
\hline
\end{tabular}

MDP: 10-methacryloxydecyl dihydrogen phosphate; HEMA: 2-hydroxyethyl methacrylate; PI: photoinitiator; CA: catalyst; MDPB: 12-methacryloyloxydodecylpyridinium bromide; MFM: multifunctional methacrylate; NaF: sodium fluorite; Bis-GMA: 2,2-bis[4-(2-hydroxy-3-methacryloxypropoxy) phenyl]propane; TEGDMA: triethylene glycol dimethacrylate

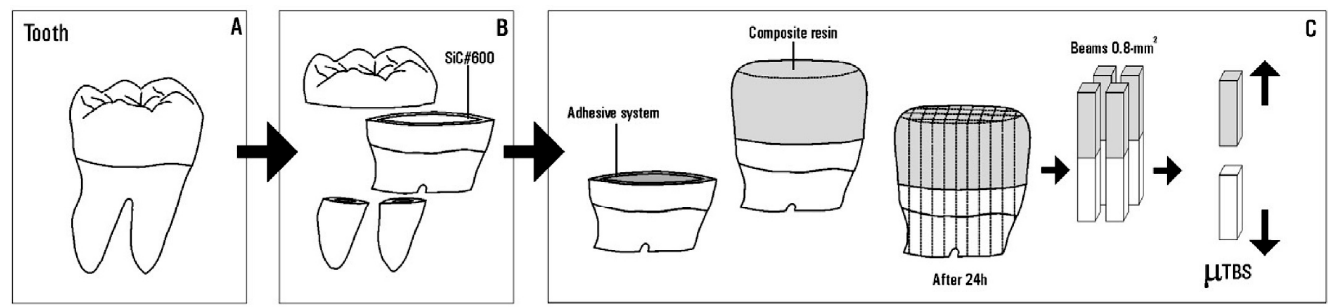

Fig. 1 Specimen preparation ( $\mu$ TBS). 
USA).

3) Microtensile test

After the specimens had been stored in distilled water at $37^{\circ} \mathrm{C}$ for 24 hours, the bonded samples were sectioned perpendicular to the adhesive interface into serial slabs with a diamond saw under water lubrication. Each slab was further sectioned to obtain beams with an adhesive area of approximately 0.8 $\mathrm{mm}^{2}$.

Then, the specimens were fixed to a testing apparatus with a cyanoacrylate adhesive (Zapit, Dental Ventures of American, Anaheim, USA) and subjected to microtensile testing at a crosshead speed of $1 \mathrm{~mm} /$ min (EZ Test, Shimadzu Co., Kyoto, Japan) (Fig. 1C). The mean bond strengths obtained were analyzed using the Kruskal-Wallis one-way analysis of variance on Ranks test. The fractured beams of debonded specimens were sputter-coated with gold and observed under a SEM (JSM-5310LV, JEOL, Tokyo, Japan) to determine the mode of failure. Failure modes were classified into four groups: (1) failure in adhesive resin; (2) failure at hybrid layer; (3) failure in dentin; and (4) mixed failure between hybrid layer and partial failure in adhesive resin.
Experiment 2 - SEM interfacial observation after acid-base challenge

Approximately $1.5 \mathrm{~mm}$-thick dentin disks were obtained from the midcoronal portion of each tooth with the use of a diamond saw under running water (Fig. 2A). Two disks were obtained from each tooth (Fig. 2B). Each surface of the dentin disk was ground with 600-grit silicon carbide paper under running water for 60 seconds (Fig. 2C), and the adhesive system was applied. Bonding procedures were conducted in the same manner as previously described.

After applying the bonding resin, a thin layer of a low-viscosity composite resin, Metafil flo (Sun Medical, Moriyama, Japan), was placed between two disks and light-activated to produce a dentin disk sandwich. The resin-tooth bonded specimens were stored in distilled water at $37^{\circ} \mathrm{C}$ for 24 hours. Subsequently, the dentin disk sandwich was vertically sectioned at the dentin-adhesive interface (Fig. 2D), and the blocks of dentin disk sandwich were embedded in epoxy resin.

Specimens were subjected to an acid challenge by being immersed in a buffered demineralizing solution $\left(2.2 \mathrm{mmol} / \mathrm{L} \mathrm{CaCl} 2,2.2 \mathrm{mmol} / \mathrm{L} \mathrm{NaH}_{2} \mathrm{PO}_{4}\right.$, and 50 $\mathrm{mmol} / \mathrm{L}$ acetic acid) adjusted to $\mathrm{pH} 4.5$ for 90

Table 2 Application procedures of adhesive systems

\begin{tabular}{ll}
\hline \multicolumn{1}{c}{ Group } & \multicolumn{1}{c}{ Application procedure } \\
\hline Clearfil SE Bond (SE) & $\begin{array}{l}\text { Primer: apply 20s, air-dry } \\
\text { Adhesive: apply and light-cure 10s }\end{array}$ \\
Clearfil Protect Bond (PB) & $\begin{array}{l}\text { Primer: apply 20s, air-dry } \\
\text { Adhesive: apply and light-cure 10s }\end{array}$ \\
Primer: SE & Primer: apply 20s, air-dry \\
Adhesive: PB & Adhesive: apply and light-cure 10s \\
Primer: PB & Primer: apply 20s, air-dry \\
Adhesive: SE & Adhesive: apply and light-cure 10s \\
\hline
\end{tabular}

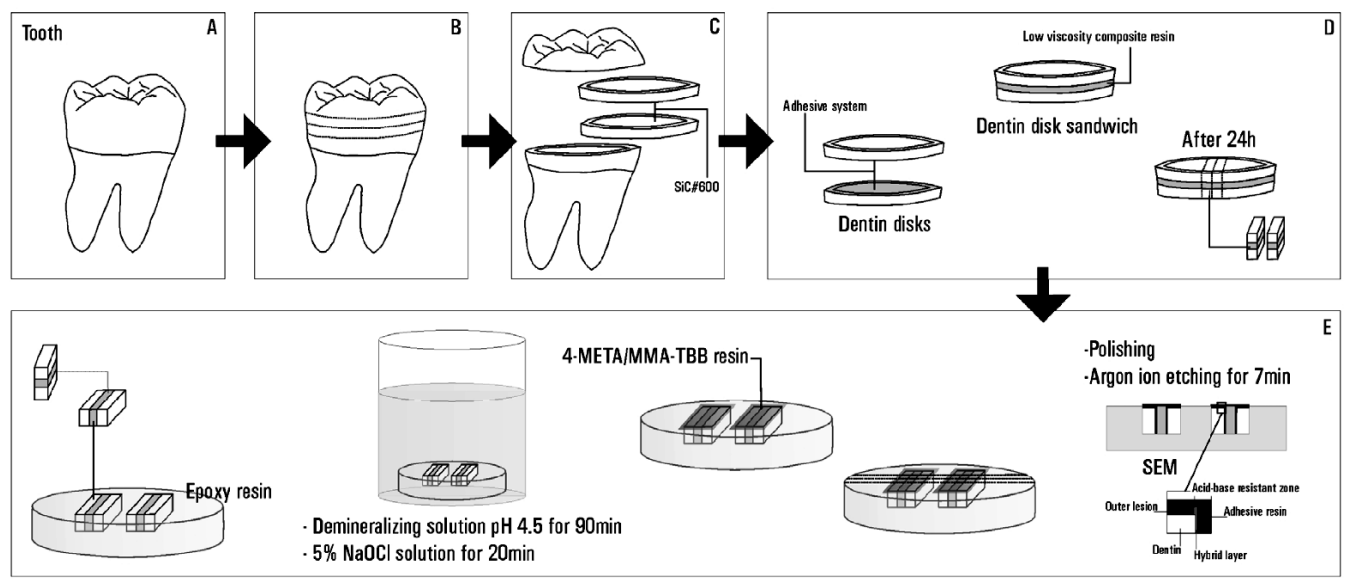

Fig. 2 Specimen preparation (SEM). 
minutes. In a pilot study, the time for acid challenge was determined by SEM observation of the artificial caries lesion being of approximately $10 \mu \mathrm{m}$ depth. After the acid challenge, specimens were immersed in 5\% sodium hypochlorite solution for 20 minutes to remove any demineralized dentin collagen fibrils, and then rinsed with running water for 60 seconds.

After which, a 4-META/MMA-TBB resin (Super Bond C\&B, Sun Medical, Moriyama, Japan) was applied to protect the demineralized surface from the polishing procedure. The samples were then vertically sectioned at the dentin-adhesive interface and polished with diamond pastes down to $0.25 \mu \mathrm{m}$. The polished samples were etched with an argon ion beam (EIS-IE, Elionix, Tokyo, Japan) for seven minutes for distinct ultrastructural identification of the dentin-adhesive interface (Fig. 2E). Following which, the samples were sputter-coated with gold, and the morphological changes of the dentin-adhesive interface produced by acid-base challenge were observed under a SEM.

\section{RESULTS}

Microtensile bond strength results

Mean bond strengths and standard deviations are shown in Table 3 . There were no significant differ-

Table 3 Results of microtensile bond strength test

\begin{tabular}{lc}
\hline \multicolumn{1}{c}{ Group } & $\mathrm{MPa}$ (SD) \\
\hline Clearfil SE Bond (SE) & $51.30(19.6)^{*}$ \\
Clearfil Protect Bond (PB) & $47.64(10.7)^{*}$ \\
Primer: SE/Adhesive: PB & $54.99(10.0)^{*}$ \\
Primer: PB/Adhesive: SE & $53.85(12.6)^{*}$ \\
\hline
\end{tabular}

*Indicate no statistically significant differences $(p=0.538)$ according to Kruskal-Wallis one-way analysis of variance on Ranks ences among the groups $(p=0.538)$. The results suggested that the incorporation of an antibacterial monomer in the primer and a fluoride-releasing material in the adhesive did not compromise the microtensile bond strength values.

Failure mode proportions of the debonded specimens are shown in Fig. 3. Most of the failures were adhesive or mixed failures regardless of the group.

\section{Scanning electron microscopic analysis}

Fig. 4 shows the representative SEM images from each group analyzed in this study. Outer lesions and acid-base resistant zones were observed in all specimens. Depth of the outer lesion ranged from 7 to $10 \mu \mathrm{m}$ after acid-base challenge. In parallel, a thin hybrid layer - approximately $0.5 \mu \mathrm{m}$ thick - was also observed in all groups. SEM analysis showed that the structures of both adhesive and hybrid layer were not damaged after acid-base challenge, regardless of the material used.

Fig. 4a of SE/SE shows the interface of Clearfil SE Bond adhesive system and dentin. The presence of the acid-base resistant zone (approximately $0.5 \mu \mathrm{m}$ thick) beneath the hybrid layer was clearly observed. Similarly, the acid-base resistant zone was observed when PB primer and SE adhesive were applied (Fig. 4d). The observed acid-base resistant zone was homogeneous and parallel to the hybrid layer. On the other hand, the interfaces of Clearfil Protect Bond group and SE primer/PB adhesive group (Figs. $4 \mathrm{~b}$ and 4c) showed sharp formation of a thick acid-base resistant zone (over $1.0 \mu \mathrm{m}$ thick) adjacent to the hybrid layer. Further, the acid-base resistant zone was formed from the upper slope to the end of outer lesion. Therefore, the thick acid-base resistant zone adjacent to the hybrid layer could be observed only when the fluoride-releasing adhesive was used.

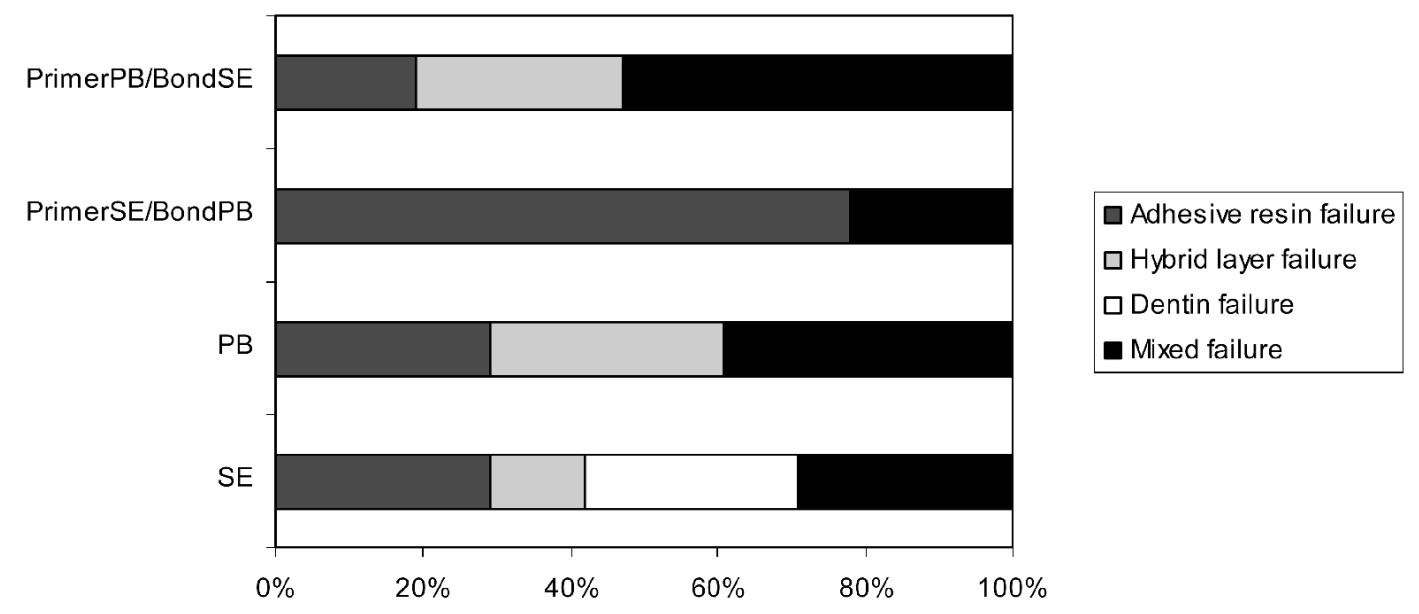

Fig. 3 Incidence (\%) of failure patterns according to SEM analysis. 

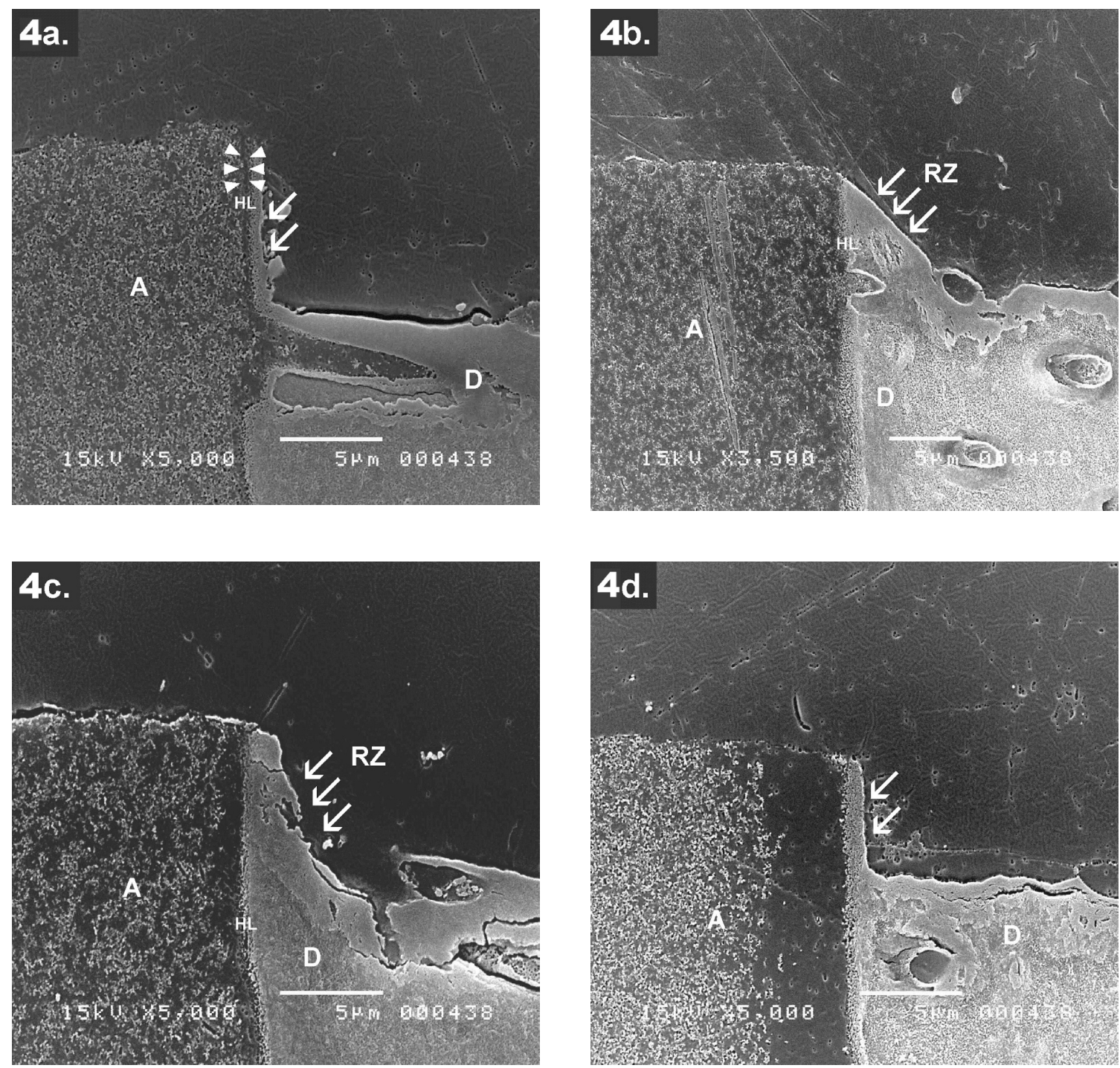

Fig. 4 SEM images of the ultrastructure of the interfaces after acid challenge.

(a) SE/SE Clearfil Se Bond: Acid resistant zone of approximately $0.50 \mu \mathrm{m}$ width (arrows) could be clearly observed beneath the hybrid layer (center of arrowheads); it is a thin and homogeneous zone parallel to the hybrid layer;

(b) PB/PB Clearfil Protect Bond: Thick acid-base resistant zone could be observed close to the hybrid layer, and which slopes from the top of the outer lesion;

(c) SE/PB Primer of CSE and Adhesive of CPB: Similar to the adhesive interface of CPB, a thick acid-base resistant zone over $1.0 \mu \mathrm{m}$ wide (arrows) was observed;

(d) $\mathrm{PB} / \mathrm{SE}$ Primer of $\mathrm{CPB}$ and Adhesive of CSE: Thin acid-base resistant zone of approximately 0.50 $\mu \mathrm{m}$ width could be observed (center of arrowheads).

$\mathrm{A}=$ adhesive resin; $\mathrm{D}=$ dentin; $\mathrm{HL}=$ hybrid layer; and $\mathrm{RZ}=$ acid-base resistant zone.

\section{DISCUSSION}

Fluoride release from restorative materials has been extensively researched for many years ${ }^{5,10,11)}$. This is because fluoride has been shown to exhibit anticariogenic activity by increasing enamel and dentin resistance to subsequent acid attack as well as inhibit carbohydrate metabolism in dental plaque. It has been widely accepted that fluoride could facilitate remineralization or prevent demineralization of the dental structure ${ }^{10,12)}$.

Currently, composite resins have been selected as the major direct restorative material in clinical dental practice. Against this background, manufacturers have been trying to develop various fluoride-releasing adhesive systems and composite resins ${ }^{13)}$. Studies have reported that fluoride-containing dentin adhesives may release fluoride into marginal gaps, and 
thereby exert a beneficial effect on adjacent demineralized enamel and dentin ${ }^{8,14)}$.

In addition, the presence of a fluoride-releasing component in dentin bonding is advantageous in that it imparts its inherent antimicrobial properties ${ }^{6)}$. For this reason, antibacterial monomers have been developed and incorporated in dental resins $s^{6,15)}$. In particular, Imazato et $a l^{16)}$ demonstrated that the antibacterial monomer, MDPB, synthesized from quaternary ammonium dodecylpyridinium, could be considered as the most promising candidate to be accepted as a true non-agent-releasing antibacterial monomer $^{13,17,18)}$.

Several reports ${ }^{19-21)}$ have established that selfetching primer/adhesive systems could certainly be used in restorative dentistry because of their ability to provide efficient marginal sealing. However, even if an adhesive system shows high bond strength, secondary caries is still found in clinical resin restorations after long-term use.

The primer of $\mathrm{PB}$ has an antibacterial monomer (MDPB), and the adhesive has a fluoride-releasing component (treated sodium fluoride). On the other hand, Clearfil SE Bond is an antibacterial-free adhesive system. The objective of this study, therefore, was to verify the influence of interchanging both self-etching primer and adhesive resin (SE and $\mathrm{PB}$ ) on microtensile bond strength, as well as in the morphology of dentin-adhesive interface after acid-base challenge. In this way, the independent effectiveness and interference from the primer and adhesive of these adhesive systems could be observed.

From the microtensile bond strength test results, there were no statistically significant differences among the groups ${ }^{7,22)}$. These results corroborated those of Imazato et $a l .^{23,24)}$, whereby it was found that the incorporation of MDPB into dentin primer did not demonstrate any adverse effect on the bond strength or curing behavior ${ }^{25)}$ of the adhesive system. Regarding the presence of a fluoride-releasing component in the adhesive resin, several studies ${ }^{6,24,26-29)}$ have established the ability of fluoride ions to inhibit secondary caries by the remineralization of dentin around the restoration. According to Han et $a l^{8)}$, although the mechanism of fluoride action on caries reduction is not fully understood for clinical use, fluoride-releasing adhesive resins and luting cements are useful in preventing the initiation of the caries process and the development of secondary caries in restored teeth.

Nakajima et $a l .{ }^{30)}$ reported that the durability of dentin bonding created by a fluoride-releasing adhesive did not change after six-month storage, as compared to the significant decrease in bond strength with a fluoride-free adhesive. They hypothesized that the fluoride component somehow prevented the degradation of dentin, resulting in the improvement of long-term stability at the dentin interface.
Although this study did not specifically evaluate the influence of each component of the adhesive systems (Table 1) on microtensile bond strength, we could conclude that the presence of fluoride-releasing component in the adhesive system did not alter the bond strength values when compared with a nonfluoride adhesive. Therefore, based on the microtensile bond strength test results, PB could be considered a reliable adhesive system for clinical use - with due consideration to its antibacterial activity too.

Besides the high bond strength values, PB exhibited a significant behavior in the acid-base challenge. A demineralizing solution was used to induce the acid attack, and $5 \% \mathrm{NaOCl}$ solution was used to remove demineralized dentin collagen fibrils ${ }^{9)}$. An acidbase resistant zone formation was clearly observed through the SEM images. This zone was formed beneath the hybrid layer with or without fluoridereleasing component. Therefore, the SEM method was useful for analyzing the ultrastructural morphology of the dentin-adhesive interface after acidbase challenge $\mathrm{e}^{9)}$. Moreover, the argon ion etching technique allowed the hybrid layer to be visibly distinguished from the dentin-resin interface ${ }^{31)}$.

Toba et $a l .^{32)}$ stated that by means of confocal laser scanning microscopy, experimental ABF was found to be effective in inhibiting artificial secondary caries around restorations ${ }^{29)}$. Nevertheless, thickness of the inhibition zone was relatively thinner than those created with conventional glass-ionomer cements ${ }^{4,32)}$.

We speculated that the formation of a thick acidbase resistant zone was related to the presence of fluoride-releasing component in the adhesive $\operatorname{resin}^{26,27,33)}$. This was because the formation of a thicker acid-base resistant zone took place only when the fluoride-containing adhesive was used (Figs. 4b and $4 \mathrm{c}$ ). Therefore, the formation of acid-base resistant zone was material-dependent ${ }^{34)}$. Further, Torii et $a l^{4)}$ suggested that fluoride-releasing adhesive systems may enhance the mineralization of decalcified dentin beneath composite resins and thereby contribute to the longevity of restorations.

With the fluoride-free adhesive system, a thin and homogeneous acid-base resistant zone (approximately $0.5 \mu \mathrm{m}$ thick) was detected along the interface between dentin and adhesive. According to Tsuchiya et $a l .^{9)}$, the existence of the acid-base resistant zone suggested that the monomer had penetrated deeper than the hybrid layer - which was revealed by argon ion etching. Moreover, the micromechanical attachment of adhesive to dentin is acid-base resistant. This could be observed even after acid-base challenge.

Carvalho et $a l^{35)}$ demonstrated that with some mild self-etch adhesive systems, a zone of partially demineralized but uninfiltrated dentin was formed beneath the hybrid layer. They speculated that due to 
the reduced etching potential of acidic monomers toward the base of hybrid layers, spaces containing products formed by dissolved calcium and phosphate ions during self-etching were created. Hence, a possible explanation for the presence of a thick acid-base resistant zone adjacent to the hybrid layer after acidbase attack, when the fluoride-releasing adhesive was used, was that fluoride was released to those spaces beneath the hybrid layer. As a result, the reaction of fluoride and other products prevented the demineralization of dental structure.

According to Itthagarun et $a .^{1}{ }^{1)}$, the fluoride released from bonded fluoride-releasing restorative materials and the potential benefit of artificial caries inhibition are indirect indications of the permeability of dentin adhesives and hybrid layers to water and ion movement. In addition, Ferracane et $a l^{14)}$ reported that a fluoride-containing adhesive released fluoride into the microspaces of a restored cavity, and thus offered some degree of protection from demineralization and recurrent caries.

Although the characteristics of the acid-base resistant zone are still unclear, analysis from the current study adequately suggested that the acid-base resistant zone formation was due to monomer penetration and fluoride release. This was especially observed when the fluoride-containing adhesive of Clearfil Protect Bond was used, since its acid-base resistant zone (over $1.0 \mu \mathrm{m}$ thick) was thicker than that formed with Clearfil SE Bond (approximately $0.5 \mu \mathrm{m}$ thick).

Previous experiments ${ }^{36-38)}$ have shown the evident nanoleakage within the hybrid layer from nonfluoride-releasing self-etching primer/adhesive systems. Through this study, it was shown that the use of self-etching primer/adhesive systems containing an antibacterial monomer (MDPB) and a fluoride-releasing component was beneficial. Apart from rendering protection against secondary caries formation and progression ${ }^{32)}$, these materials allowed significant bond strength to be yielded. As fluoridereleasing adhesives are in direct contact with the cavity wall, fluoride ions released from them easily penetrate and diffuse into the dentin at the cavity wall $^{32)}$.

The progression rate of secondary caries is an important factor that determines the longevity of restorations. As such, further work should be carried out with regard to long-term antibacterial efficacy, as well as the quality and stability, of the acidbase resistant zone beneath the hybrid layer against caries progression.

\section{ACKNOWLEDGEMENTS}

The authors are grateful to the Kuraray Medical Company for supplying the materials tested. This study was supported in part by a grant from the
JICA - Japan International Cooperation Agency, and by a grant-in-aid from the Center of Excellence Program for Frontier Research on Molecular Destruction and Reconstruction of Tooth and Bond at Tokyo Medical and Dental University, Japan.

\section{REFERENCES}

1) Itthagarun A, Tay FR, Pashley DH, Wefel JS, GarcíaGodoy F, Wei SHY. Single-step, self-etch adhesives behave as permeable membranes after polymerization. Part III: Evidence from fluid conductance and artificial caries inhibition. Am J Dent 2004; 17: 394-400.

2) Fontana M, González-Cabezas C. Secondary caries and restoration replacement: an unresolved problem. Compend Contin Educ Dent 2000: 21: 15-26.

3) Kidd EAM, Toffenetti F, Mjör IA. Secondary caries. Int Dent J 1992; 42: 127-138.

4) Torii Y, Itota T, Okamoto M, Nakabo S, Nagamine M, Inoue K. Inhibition of artificial secondary caries in root by fluoride-releasing restorative materials. Oper Dent 2001; 26: 36-43.

5) Preston AJ, Mair LH, Agalamanyi EA, Higham M. Fluoride release from aesthetic dental materials. J Oral Rehab 1999; 26: 123-129.

6) Imazato S. Antibacterial properties of resin composites and dentin bonding systems. Dent Mat 2003; 19: 449457.

7) Yoshiyama M, Doi J, Nishitani Y, Itota T, Tay FR, Carvalho RM, Pashley DH. Bonding ability of adhesive resins to caries-affected and caries-infected dentin. J Appl Oral Sci 2004; 12: 171-176.

8) Han L, Edward C, Okamoto A, Iwaku M. A comparative study of fluoride-releasing adhesive resin materials. Dent Mat J 2002; 1: 9-19.

9) Tsuchiya $S$, Nikaido $T$, Sonoda $H$, Foxton RM, Tagami J. Ultrastructure of the dentin-adhesive interface after acid-base challenge. J Adhes Dent 2004; 6: 183-190.

10) Featherstone JDB. Fluoride, remineralization and root caries. Am J Dent 1994; 7: 271-274.

11) Ingram GS, Nash PF. A mechanism for the anticaries action of fluoride. Caries Res 1980; 14: 298-303.

12) ten Cate JM. Remineralization of caries lesions extending into dentin. J Dent Res 2001; 80: 1407-1411.

13) Imazato $S$, Torii $M$, Takatsuka $T$, Inoue $K$, Ebi $N$, Ebisu S. Bactericidal effect of dentin primer containing antibacterial monomer methacryloyloxydodecylpyridinium bromide (MDPB) against bacteria in human carious dentin. $J$ Oral Rehab 2001; 28: 314-319.

14) Ferracane JL, Mitchem JC, Adey JD. Fluoride penetration into the hybrid layer from a dentin adhesive. Am J Dent 1998; 11: 23-28.

15) Phanthavong $S$, Harada $N$, Sonoda $H$, Nikaido $T$, Pereira PNR, Tagami J. Fluoride release and microhardness of one-step adhesives in two immersion solutions. Int Chin J Dent 2004; 4: 1-7.

16) Imazato S, Russell RRB, McCabe JF. Antibacterial activity of MDPB polymer incorporated in dental resin. 
J Dent 1995; 23: 177-181.

17) Imazato S, Ehara A, Torii M, Ebisu S. Antibacterial activity of dentine primer containing MDPB after curing. J Dent 1998; 26: 267-271.

18) Imazato S, Ebi N, Takahashi $\mathrm{Y}$, Kaneko T, Ebisu S, Russell RRB. Antibacterial activity of bactericideimmobilized filler for resin-based restoratives. Biomat 2003; 24: 3605-3609.

19) Takahashi A, Sato Y, Uno S, Pereira PNR, Sano H. Effects of mechanical properties of adhesive resins on bond strength to dentin. Dent Mater 2002; 18: 263-268.

20) Toledano M, Osorio R, Ceballos L, Victoria Fuentes M, Fernandes CAO, Tay FR, Carvalho RM. Microtensile bond strength of several adhesive systems to different dentin depths. Am J Dent 2003; 16: 292-298.

21) Sano H, Yoshikawa T, Pereira PNR, Kanemura N, Morigami M, Tagami J, Pashley DH. Long-term durability of dentin bonds made with a self-etching primer, in vivo. J Dent Res 1999; 78: 906-911.

22) Yoshiyama M, Tay FR, Doi J, Nishitani Y, Yamada T, Itou K, Carvalho RM, Nakajima M, Pashley DH. Bonding of self-etch and total-etch adhesives to carious dentin. J Dent Res 2002; 81: 556-560.

23) Imazato S, Kinomoto $\mathrm{Y}$, Tarumi H, Torii M, Russell $\mathrm{RRB}, \mathrm{McCabe} \mathrm{JF}$. Incorporation of antibacterial monomer MDPB into dentin primer. J Dent Res 1997; 76: 768-772.

24) Imazato S, Kinomoto Y, Tarumi H, Ebisu S, Tay FR. Antibacterial activity and bonding characteristics of an adhesive resin containing antibacterial monomer MDPB. Dent Mat 2003; 19: 313-319.

25) Imazato S, McCabe JF. Influence of incorporation of antibacterial monomer on curing behavior of a dental composite. J Dent Res 1994; 73: 1641-1645.

26) Pereira PNR, Inokoshi S, Tagami J. In vitro secondary caries inhibition around fluoride releasing materials. J Dent 1998; 26: 505-510.

27) Pereira PNR, Inokoshi S, Yamada T, Tagami J. Microhardness of in vitro caries inhibition zone adjacent to conventional and resin-modified glass ionomer cements. Dent Mat 1998; 14: 179-185.

28) Itota $\mathrm{T}$, Torii $\mathrm{Y}$, Nakabo $\mathrm{S}$, Tashiro $\mathrm{Y}$, Konishi $\mathrm{N}$,
Nagamine M. Effect of fluoride-releasing adhesive system on decalcified dentin. J Oral Rehab 2003; 30: 178183.

29) Kuramoto A, Imazato S, Walls AWG, Ebisu S. Inhibition of root caries progression by an antibacterial adhesive. J Dent Res 2005; 84: 89-93.

30) Nakajima M, Okuda M, Ogata M, Pereira PNR, Tagami J, Pashley DH. The durability of a fluoridereleasing resin adhesive system to dentin. Oper Dent 2003; 28: 186-192.

31) Inokoshi S, Hosoda H, Harnirattisai C, Shimada Y. Interfacial structure between dentin and seven dentin bonding systems revealed using argon ion beam etching. Oper Dent 1993; 18: 8-16.

32) Toba S, Pereira PNR, Nikaido T, Tagami J. Effect of topical application of fluoride gel on artificial secondary caries inhibition. Int Chin J Dent 2003; 3: 53-61.

33) Okuda M, Pereira PNR, Nikaido T, Tagami J. Evaluation of in vitro secondary caries using confocal laser scanning microscope and X-ray analytical microscope. Am J Dent 2003; 16: 191-196.

34) Savarino L, Breschi L, Tedaldi M, Ciapetti G, Tarabusi C, Greco M, Giunti A, Prati C. Ability of restorative and fluoride releasing materials to prevent marginal dentine demineralization. Biomat 2004; 25: 1011-1017.

35) Carvalho RM, Chersoni S, Frankenberger R, Pashley DH, Prati C, Tay FR. A challenge to the conventional wisdom that simultaneous etching and resin infiltration always occurs in self-etch adhesives. Biomat 2005; 26: $1035-1042$

36) Suppa P, Breschi L, Ruggeri A, Mazzotti G, Prati C, Chersoni S, Di Lenarda R, Pashley DH, Tay FR. Nanoleakage within the hybrid layer: a correlative FEISEM/TEM investigation. J Biomed Mater Res 2005; 73: 7-14.

37) Tay FR, Pashley DH. Water treeing - A potential mechanism for degradation of dentin adhesives. Am J Dent 2003; 16: 6-12.

38) Tay FR, King NM, Chan K, Pashley DH. How can nanoleakage occur in self-etching adhesive systems that demineralized and infiltrate simultaneously? J Adhes Dent 2002; 4: 255-269. 